\title{
Follow the Unwritten Rules?
}

Karl Foulke was the sort of person who was impatient with bureaucratic delays when he wanted something to happen. He was well funded and outspoken, and had the ear of the dean at Great Eastern University. His most recent demand was to have his animals arrive the following week and be housed in his laboratory if no other space was available. Great Eastern's IACUC had an unwritten policy that all potential animal housing areas had to be inspected by the IACUC before their use. Perhaps it should have been in writing, but it wasn't.

Foulke placed his order for transgenic mice with a colleague at a nearby university. His protocol had IACUC approval. He knew that the Department of Animal Resources would require health certifications and would quarantine the rodents before releasing them for research use. $\mathrm{He}$ also knew that the department had little space for either quarantine or general animal housing. None of this deterred Foulke. As soon as he learned that there would be a delay in arrival of the appropriate health forms and in the provision of animal housing space, he drove to the neighboring institution and, with his colleague's consent, brought the mice back to his laboratory. They were housed in Microisolator-type cages, which in turn were placed in a Class II biological safety cabinet. His plan was to start breeding the animals and have his own technicians care for them. Then, when adequate space became available, he would somehow manage to have them moved to the Animal Resources Department.

Foulke may actually have succeeded with this scenario if the animal-care technician at his colleague's institution had not noticed that two cages were missing, but nobody had deducted them from the census sheets. One thing led to another, and eventually the house of cards came falling down. As expected, there were repercussions for the offending colleague at his own institution, but Foulke's situation was more difficult. The Great Eastern IACUC quickly determined that Foulke had bypassed not only IACUC animal housing procedures but also the Animal Resources Department's ordering procedures, and could have threatened the health of many rodents at Great Eastern. Foulke calmly responded that there was no written IACUC policy that even suggested that the Committee had to inspect an animal housing area before it was occupied, and he challenged the IACUC to show him any federal regulation that required the same. He said that he had an IACUC-approved protocol, he did submit an animal order, and, as a service to Great Eastern, he had taken the initiative to devise a way to house temporarily and safely those animals that were vital to his NIH-funded research.

The IACUC wasn't impressed and considered suspending Foulke's protocol. The Committee recognized that, although Foulke knew full well about the unwritten policy, part of the problem was of its own making. They also knew that, although the dean-who was also the Institutional Official (IO)—would not try to revoke any IACUC decision, he would not be sympathetic with anything that inhibited Foulke's research.

How would you handle this IACUC's current predicament? Is there any regulation that requires the IACUC to inspect an animal housing site before it is occupied?

\section{Show Me the Rules}

\section{James Owiny, BVM, PhD}

Assuming that Foulke has an approved protocol to breed mice, these activities with animals are subject to the Health Research Extension Act of 1985 (Public Law 99-158), the Public Health Service Policy on Humane Care and Use of Laboratory Animals (PHS Policy), the US Government Principles for the Utilization and Care of Vertebrate Animals Used in Testing, Research and Teaching (US Government Principles), and the Guide for the Care and Use of Laboratory Animals (Guide).

A critical issue for Great Eastern's IACUC is lack of a clearly written guideline on housing animals outside of the central facility. This is an opportune moment for the IACUC to review procedures it follows to meet PHS Policy requirements. An excellent starting place is the Animal Welfare Assurance statement of compliance, with which all IACUC members should be familiar. If the Assurance does not describe clearly how the IACUC functions, then it is time to amend it and develop a policy on the review of activities with animals. The IACUC should also check the latest semiannual program review to determine whether it was functioning appropriately. Minutes from previous meetings may provide documentation supporting the current IACUC's decisions and demonstrate that Foulke was not being persecuted. The Attending Veterinarian may be able to provide written procedures explaining which animals are required to undergo a quarantine procedure and for how long, as well as on the overall veterinary care program. Depending on the circumstances, it may be possible to start breeding the animals while still in quarantine, thereby supporting Foulke's research objectives. Both Foulke and the dean would appreciate such a move.

It appears that there were clearly established procedures for ordering animals into the facility. Such procedures should include a mechanism for tracking the number of animals ordered and used against those 